\title{
NCI CTEP SDC Urothelial Tract Neoplasm Category Terminology
}

National Cancer Institute

\section{Source}

National Cancer Institute. NCI CTEP SDC Urothelial Tract Neoplasm Category

Terminology. NCl Thesaurus. Code C103030.

Urothelial Tract Neoplasm is an NCl Cancer Therapeutic Evaluation Program (CTEP) Simplified Disease Classification (SDC) category used to organize cancer-related disease coding that harmonizes with and supports reporting based on the global standard Medical Dictionary for Drug Regulatory Reporting (MedDRA) terminology. 